\title{
Recent Industrial Developments of Marine Composites Limit States and Design Approaches on Strength
}

\author{
Beatrice Barsotti ${ }^{1} \cdot$ Marco Gaiotti $^{1} \cdot$ Cesare Mario Rizzo $^{1}$ \\ Received: 13 April 2020 / Accepted: 25 August 2020 / Published online: 8 October 2020 \\ (C) The Author(s) 2020
}

\begin{abstract}
To further exploit the potential of marine composites applications in building ship hulls, offshore structures, and marine equipment and components, design approaches should be improved, facing the challenge of a more comprehensive and explicit assessment of appropriately defined limit states. The structure ultimate/limit conditions shall be verified in principle within the whole structural domain and throughout the ship service life. What above calls for extended and reliable materials characterization on the one hand and for accurate and wide-ranging procedures in structural analyses. This paper presents an overview of recent industrial developments of marine composites limit states assessments and design approaches, as available in open literature, focusing on pleasure crafts and yachts as well as navy ships and thus showing a starting point to fill the gap in this respect. After a general introduction about composites characterization techniques, current design practice and rule requirements are briefly summarized. Both inter-ply and intra-ply failure modes and corresponding limit states are then presented along with recently proposed assessment approaches. Three-dimensional aspects in failure modes and manufacturing methods have been identified as the main factors influencing marine composite robustness. Literature review highlighted also fire resistance and hybrid joining techniques as significant issues in the use of marine composites.
\end{abstract}

Keywords Marine composites $\cdot$ Navy ships $\cdot$ Pleasure crafts $\cdot$ Yachts $\cdot$ FEM $\cdot$ Material characterization $\cdot$ Limit state design · Ultimate strength

\section{Introduction}

This paper deals with marine composites and it is intended as a review paper aimed at supporting structural design and analysis in this particular field. While many papers and books are available in open literature about composite materials and outstanding experimental, numerical and theoretical results by many researchers were and still continue to be presented, it was felt desirable to offer a paper specifically dedicated to

\section{Article Highlights}

- Application of composites in marine industry is reviewed aiming at filling the gap between design practice and construction in shipyards;

- Design approaches need to be improved becoming more transparent, design oriented and based on limit states to exploit composites potential;

- The focus is on pleasure crafts and yachts as well as navy ships.

Cesare Mario Rizzo

cesare.rizzo@unige.it

1 DITEN, Marine Structures Testing Lab, Polytechnic School, University of Genoa, Via Montallegro, 1, Genoa, Italy marine composites with special focus on pleasure crafts and yachts as well as navy ships.

In particular, a few Italian shipyards are specialized in building the above-mentioned units supported by relevant material manufacturers and service-suppliers as well as by research and educational activities ongoing since decades in the field. Therefore, a recent literature review paper on the matter appeared enviable. This paper focuses on the last five years literature and current state of the art of industrial practice and possible mid-term innovations, a topic which is not covered by scientific literature often.

In the following, some very basic concepts are briefly outlined to introduce the matter before presenting latest advancements in the field.

Marine composites are typically constituted by multilayered laminates, where each ply is traditionally represented by an orthotropic layer, from a mechanical point of view. An orthotropic material admits three symmetry planes; thus, the resulting elastic matrix is defined by 9 independent elastic constants in 3-dimensional space, and by 4 elastic constants considering a plane stress condition, which is often the case 
for marine structures applications, characterized by relatively small thicknesses if compared with other dimensions.

Basic mechanical principles underpinning the marine composites analysis are the following:

- The typical fiber-reinforced marine composite is constituted by a polymeric matrix, which cures on the reinforcing fibers, on a mold.

- The fibers sustain the load, in terms of stresses, and provide the material stiffness;

- Moreover, the fibers also act as crack stopper, limiting the fracture propagation, originating both in the matrix and in the fiber.

- On the other hand, the matrix equally distributes the loads among fibers and provide the interlaminar shear strength.

- Its tasks are also to resist against chemical aggressions and to allow an ultimate deformation higher than the one of fibers, to prevent from matrix failure at low fiber stress.

The above-mentioned features are more and more applied in ship and offshore structures, not only in small crafts and special units, but also for navy and merchant ship structural components, propulsion systems and hull outfitting. Most of these applications were driven by the need to overcome corrosion problems experienced with steel or aluminum alloys or environmental degradation suffered by wood. Another reason for using composite was to reduce weight, particularly the topside weight of ships. A detailed description of the application of composites in marine industry is given by the works of Selvaraju and Ilaiyavel (2011) and Mouritz et al. (2001), where, for each application, the major benefits and main drawbacks gained from using composites instead of conventional shipbuilding materials, such as steel and aluminum alloys, are identified.

Most of marine structural composites employ E-glass fibers in an unsaturated polyester resin matrix. Where higher stiffness is required, and cost allows, the structures may be manufactured using carbon fiber-reinforced epoxy resin. Different types of reinforcement and matrix materials may be selected to meet the design requirements and end-of-life considerations for a specific application. As told before, the matrix is the medium that transfers load from the external environment into the reinforcement fibers and, if the matrix is polymeric (PMC, polymer matrix composite), it is possible to distinguish mainly two different products: thermosetting resins, that are generally of single use (i.e., not inclined to easy recycling) and thermoplastic-matrix systems that can be recycled with relative ease. The principal commercial groups of thermosetting resins are phenolic resins, epoxy, unsaturated polyester, and vinyl ester. These materials are normally supplied as a liquid resin that can be solidified using chemicals and heat. The principal thermoplastic polymers to find use as the matrix for composites are polypropylene, polyamide, polyester, and PEEK (Pemberton et al. 2019). As regards reinforcement, a wide variety of fibers may be used and they are generally classified as natural (plant, animal, or mineral based) and synthetic fibers (nylon, acrylic, aromatic polyester, polyethylene, aramid, glass, carbon, boron, silicon carbide, stainless steel, aluminum, etc.). Glass, carbon or aramid fibers are the most common choices and obviously they are characterized by very different mechanical properties. In particular:

- Glass is the dominant reinforcement fiber in composite construction, accounting for over $90 \%$ of worldwide application. It has good strength to weight characteristics, can be produced easily and sold at a low price. When fiberglass is impregnated with epoxy resin, the resulting composite has high tensile strength and is stronger than steel on an equal weight basis. Glass fiber is made by melting the constituent materials together and drawing the melt into a fiber. They have a diameter of 5-25 $\mu \mathrm{m}$ and are coated with a "sizing" to improve the adhesion with the matrix material. The three most common types of glass fiber are E-glass, C-glass, and S-glass; the others are usually associated with a particular manufacturer.

- E-glass (electrical) is the most commonly used fiber in PMCs. It has good strength and stiffness but poor impact properties. The "E" refers to the electrical resistance of the fibers;

- C-glass (chemical or corrosion) fibers have good chemical resistance and are often used as a veil or tissue outer layer on pipes or tanks rather than as a reinforcement;

- S-glass (stiffness) is a glass fiber with improved mechanical and thermal properties.

Generally, when cost is a major driving force in the selection of a reinforcing material, fiberglass is usually preferred.

- Carbon fiber is the most expensive, but it has the best specific stiffness properties. It is available in different grades, categorized by the modulus of the fiber, increasing in cost as the modulus increases. The standard modulus fibers are referred to as high strength (HS); then there are intermediate modulus (IM), high modulus (HM), and ultrahigh modulus (UHM). Although carbon fiber has very good tensile strength and modulus, they have low impact strength and the highest modulus fibers can be brittle (Goodship et al. 2016).

- Aramid fibers, specified for its excellent impact resistance, have a unique combination of high modulus, high strength, toughness, thermal stability, and chemical resistance. However, due to the molecular arrangement, the fibers have poor transverse strength and poor compressive properties (compressive strength is generally about $20 \%$ of tensile strength). 
Fibers can be arranged in a variety of different ways. The configuration of the reinforcement sets ranges for both the achievable fiber volume fraction and the reinforcing efficiency. In particular, fibers can either have a non-specific arrangement like in the case of chopped fiber (nonwovens) or long fibers grouped together, called tows or yarns, and assembled into fabrics such as wovens, braids, or knits. Since the fibers are the main source for the stiffness and strength of polymer matrix composites, it could be correctly assumed that the direction of these fibers will play a key role in the mechanical and thermal behavior of the composite. The more the fibers are aligned in the load direction, the higher are the stiffness and strength of the composite in these directions. Hence, a chopped nonwoven glass composite with fibers randomly oriented in many directions will have stiffness inferior to that of a fabric composite with fibers aligned in the load direction, and so on. PMCs are typically manufactured using the process of stacking lamina or fabrics. In some cases, these fiber layers are pre-impregnated with a resin (prepregs) and kept at a very low temperature to slow down the chemical reaction for at least 6 months or even a year. These layers are typically placed in the expected load directions of the target product for an optimum design. After stacking, if the fibers are not pre-impregnated, resin is introduced to the composite and cured, or, in the case of prepregs, heat is applied to initiate the curing process (Gowayed 2013).

In the following, some peculiars aspects are considered resulting from literature and industrial review of the last few years, aimed at emphasizing current practices in composite shipbuilding and future trends. Earlier findings and general descriptions may be found in Tsai and Hahn (1980), Shenoi and Wellicome (1993) and Jones (1998).

\section{Mechanical Aspects and Current Design Practice}

The mechanics of composites should be approached separately, considering micro-mechanical and macro-mechanical aspects.

The micro-mechanics considers the interaction between fiber and matrix in the isolated ply, assumed as linear-elastic orthotropic, and defines the elastic constants derived from analytical formulations or, when available, from experiments.

When dealing with micro-mechanics, the interface between fiber and matrix also play a key role in the failure mode, in particular when dealing with fatigue and fracture, as well as dynamic loading. Due to chemical issues related to the different ionicity of matrix and fiberglass, sizing is always necessary to improve fiber impregnability and fiber-matrix bonding. Sizing is the chemical substance which is sprayed on fiberglass just after the fibring process, having an intermediate ionicity between fiberglass and matrix, in order to prevent the fibers from repulsing the matrix during the impregnation process, often resulting in sharp corner voids inside the matrix.

From this perspective, carbon fiber is less critical and does not require sizing application in general, although recent innovations made available sizing for carbon, to improve the laminate performance (Andideh and Esfandeh 2017; Kobayashi et al. 2017). The fiber-matrix cohesive parameters may determine the predominant damage mode in particular stress conditions, as recently investigated by Ma and Liu (2016). Fiber bridging effects in fatigue problems were investigated by Olave et al. (2015), while Airoldi et al. (2015) showed the influence of fiber bridging in delamination problems. Russo et al. (2019) have demonstrated the strong impact of the fiber bridging toughening mechanisms on the delamination propagation and, consequently, on the ultimate strength of composite structures.

In conclusion, if the general trend for the past decades aimed at maximizing the fiber-matrix cohesive strength, nowadays the global cohesive aspects are considered, and parameters like fracture toughness are believed to have a greater impact on the operative life of the composite.

Current practice ignores completely the micro-mechanical aspects, being too complex to be approached by ship scantling designers, and include its effect in a general comprehensive failure mode of the lamina.

Best practice involves experiments to determine failure behavior of composites, on a macro scale, and associated failure modes in a micro scale, although such experimental efforts are generally not available to most shipbuilding; hence, failure modes are often assumed from rules, literature review, or from reports from producers.

The present paper is not comprehensively discussing about current rules for composite hull scantling as they are mainly empirically driven, but it is worth noting that basically quasiisotropic approaches are ruled by classification societies, while more modern methods are left under the own responsibility of the designer. Some aspects such as the effective breadth calculations, are still widely discussed in literature (e.g., Ghelardi et al. 2015). However, the work by Ghelardi et al. does not claim to settle all uncertainties about the effective breadth for composite stiffened panels for marine structures. These uncertainties, combined with those from production, lead to over conservative rules formulations. Actually, most classification societies rules for pleasure crafts made of composite materials suggest empirical formulations to characterize the main laminate properties (e.g., tension and bending ultimate strength) depending on the fiber content but without accounting for actual stacking sequence and non-isotropic behavior. Only HSC rules (International Maritime Organization 2000) recently overcame the limitation, although orthotropic properties are only available for the definition of stiffness, being the failure check completely uncovered by such rules. 
Analytical formulations like the so-called mixture rule are well established and provide reliable results in terms of axial modulus and in-plane Poisson coefficients, starting from fiber and matrix properties. On the other hand, empirical corrections derived from experimental campaigns are still necessary to overcame limits originating from simplified assumptions in order to define the remaining elastic constants. Among the others, the Halpin-Tsai correction, and its further evolutions, is still likely the most popular in current literature and design practice (Halpin and Kardos 1976), despite based on rather dated experiments.

More difficult is to predict reliable data for the ultimate strength of the lamina, as the manufacturing process has a strong impact on such parameters and composites obtained from very same fibers and matrix can show completely different behaviors. Manufacturing imperfections, like air inclusions, de-cohesions and fiber misalignment, and chemical features, i.e., the influence of ambient and laminate temperature while curing and humidity, may seriously affect the composite strength as well as its failure modes. This aspect is widely covered in literature and confirmed in recent works by Godani et al. (2014) and Kim et al. (2014), who investigated the mechanical properties and failure mechanisms of the GFRP composite materials including the hand lay-up processed, the vacuum infusion processed and the hybrid GFRP composites, particularly focusing on interlaminar strength and buckling induced delaminations. Kalantari et al. (2017) studied the effects of three sources of uncertainties, namely, existence of matrix voids, fiber misalignment and thickness variation, on optimal and robust designs, with the main focus being the influence of matrix voids. The results indicated that, in general, all three uncertainties affected the cost and weight of the optimal designs with the effect of voids being more critical for void contents of greater than $2 \%$.

The above listed parameters are therefore a source of uncertainty that can be quantified and described realistically by a probabilistic formulation, supporting thus design decisions (Kharghani and Guedes Soares 2016).

At the moment, the only reliable practice to determine failure stresses of a lamina is to perform a widespread experimental activity (Kharghani and Guedes Soares 2018b, 2019, 2020) based on specimens produced under the same environmental conditions and manufacturing methods as per the actual composite. Generally, sampling of built up laminates is required by rules after construction.

\subsection{Failure Modes and Limit States}

Once the ply behavior is assessed, the prediction of the laminate response when subjected to forces and moments, is based on the so-called Classic Laminate Theory, which linearly adds the contribution of each ply to obtain the global stiffness of the composite laminate, given its stacking sequence (Bert 1989).
The theory is well established and implemented by most of the commercial finite element software when modeling multilayered composites: it provides reliable results within the material elastic range of each ply. In practice, the mid-plane strains are calculated, as well as the laminate curvatures, from equilibrium considerations. A thru-thickness linear variation of acting normal strains is assumed and the stresses are computed at each ply. Different failure models can be adopted to asses for the ply failure: currently, the most adopted by leisure boat industry is the maximum strain failure criterion. Other criteria include maximum stress, Tsai-Hill, Tsai $\mathrm{Wu}$ and their derivations.

It is worth noting that composite materials have superior properties only in the fiber direction; therefore, they also present several drawbacks, including poor in-plane compression, tension-compression fatigue, and restricted resistance to interlaminar fiber-matrix cracking and delamination due to the limited fracture toughness of the polymer matrices. These materials present in fact a number of failure modes, which is much larger if compared with traditional isotropic ductile materials, and current theories only provide approximated results to asses for the first ply failure of a single ply in the stacking sequence. In this respect, it should be mentioned the well known series of coordinated studies (known as the "WorldWide Failure Exercise," WWFE) which, since 1992, aim to provide a comprehensive description of the foremost failure theories for fiber-reinforced plastic (FRP) laminates that were available at the time, a comparison of their predictive capabilities directly with each other, and a comparison of their predictive capabilities against experimental data (Kaddour et al. 2014).

Figure 1 shows typical failure modes of marine composites, as reported by Xu et al. (2002). It is worth noting that the most advanced current design practices only account for intra-layer failure of orthotropic plies. Moreover, intra-layer failure criteria can hardly asses for the failure mode (see Figure 1, items 3, 4 or 5). Conjectures can be made considering the predominant stress component of the stress tensor. Anyway, although long-lasting discussions have been carried out in

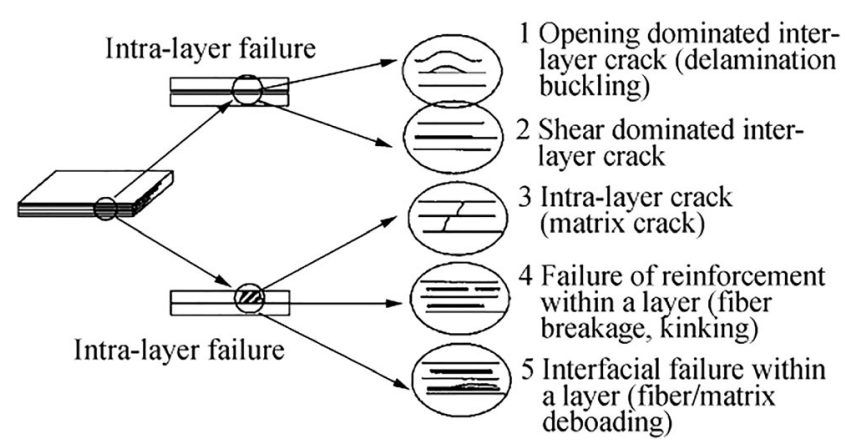

Figure 1 Typical failure modes of marine composites (Roy Xu et al. 2002) 
scientific literature for decades, no unified and well-assessed methods are currently universally recognized.

Numerical models to predict inter layer failures, as cohesive elements in finite element methods, are currently available, but actual computational costs limit their applications to small-scale model. Recently, Mohammad and Mousa (2019) presented a comprehensive assessment on the VCCT (Virtual Crack Closure Technique), CZM (Cohesive Zone Modeling) and XFEM (Extended Finite Element Method) for modeling of delamination propagation in composites: advantages and limitations of each approach are addressed and the combination of XFEM and CZM is found as a suitable method for simulation of delamination propagation. The just mentioned models can be used at the grillage scale, where they allow to study cracks propagating into the region of 2 or $3 \mathrm{~m}$ and these have been performed on marine structures to study stiffener debonding.

Moreover, the knowhow required to reliably use such numerical tools is still very far from current everyday practice of most shipbuilders' technical offices.

As a consequence, nonlinear response associated to material failure still represents a challenging task for composite materials. I.e., in order to predict the post first ply failure and collapse behavior, orthotropic "plastic" models, with a close to zero admissible plastic deformation, were successfully adopted by Maggiani et al. (2017). Such modeling strategy showed promising results for small-scale models, although its extension to the full scale is still limited by computational and modeling cost.

Finally, it is well known that laminated composite materials are also susceptible to impact damage, arising from such varied events as collisions, striking floating debris, grounding, docking or objects dropped on board during operation or fabrication. Impact damage may be dangerous not only because a breach may lead directly to a loss of the structure at sea, but also because less severe damage may leave the structure unable to support a future unusual load that would be normally within the design limits. An experimentally based study of the impact response of typical marine composites was developed by Sutherland and Guedes Soares (2011).

\subsection{Three-dimensional Aspects}

Current practice limits the understanding of composite behavior only to plane stress assumptions, and even if such approximations is true for thin laminates, reliability of numerical prediction of structural response is still quite poor (Kappel and Mittelstedt 2020).

Nonetheless, among failure modes, the most critical is indeed the delamination, which involves three-dimensional aspects. Delaminations can open and grow inside the ply, running on the interfaces between fiber and matrix, but more likely they tend to grow in the interlaminar matrix, representing the amount of resin restrained between two adjacent plies, due to interlaminar shear stresses or stresses normal to the composite plane.

It is therefore of great importance to understand the effect of delamination on the behavior and the ultimate strength of composite structures. This aspect has been studied by some researchers, e.g., Li et al. (2018) investigated the compressive properties and failure mode of reinforced composite structures having different delamination defects. Results showed that the ultimate load-carrying capacity of the specimen with delamination defects in the skin and in the stiffener under compressive load reduced by $38.58 \%$ and $22.34 \%$, respectively. Kharghani and Guedes Soares (2019) also proposed an improved and efficient analytical solution to predict the behavior and the ultimate strength of composite laminates containing delamination using the Layerwise Higher Order Shear Deformation Theory (LHSDT) combined with fracture analysis.

Mode II opening is the most common for thru-thickness delamination of composites in bending, deriving from shear stresses associated to the variation of the bending moment. Inplane shear strength is indeed an important parameter of organic matrices, for both manufacturing marine composites and bonding components. Gaiotti et al. (2020) recently investigated the parameters that characterize the bonding capability of matrices. It is found that energy release rate of the adhesive for mode II play a key role in the bonding effectiveness. Mixed-mode interlaminar fracture behavior of glass/vinyl ester composite laminate has been investigated numerically and experimentally by Alizadeh and Guedes Soares (2019).

Moreover, relevant works were conducted in recent years to predict the opening and the growth of delaminations in fiber-reinforced composites, and also to asses for their effect in terms of global response of the structure. Gaiotti et al. (2014) compared different numerical strategies to determine the buckling capacity of delaminated composite panels and Colombo and Vergani (2014) studied the effect of delamination on fatigue behavior. Considering the advances of numerical simulations in this field, although the theory was developed in the past decades, due to the high computational efforts cohesive elements have become available in finite element software only recently. This fact has introduced a new tool to simulate delamination opening and growth; however, current applications only limits to small-scale models because of two main reasons, both related to computational limits: primarily because of the higher number of elements required to simulate cohesive layers, and secondarily since cohesive are solid elements requiring a 3D solid modeling strategy.

Cohesive elements define the material response when two bonded surfaces are separated by a traction (both mode I and mode II are implemented in most commercial FE software). Three parameters are used to define the numerical law, as reported in Figure 2: 

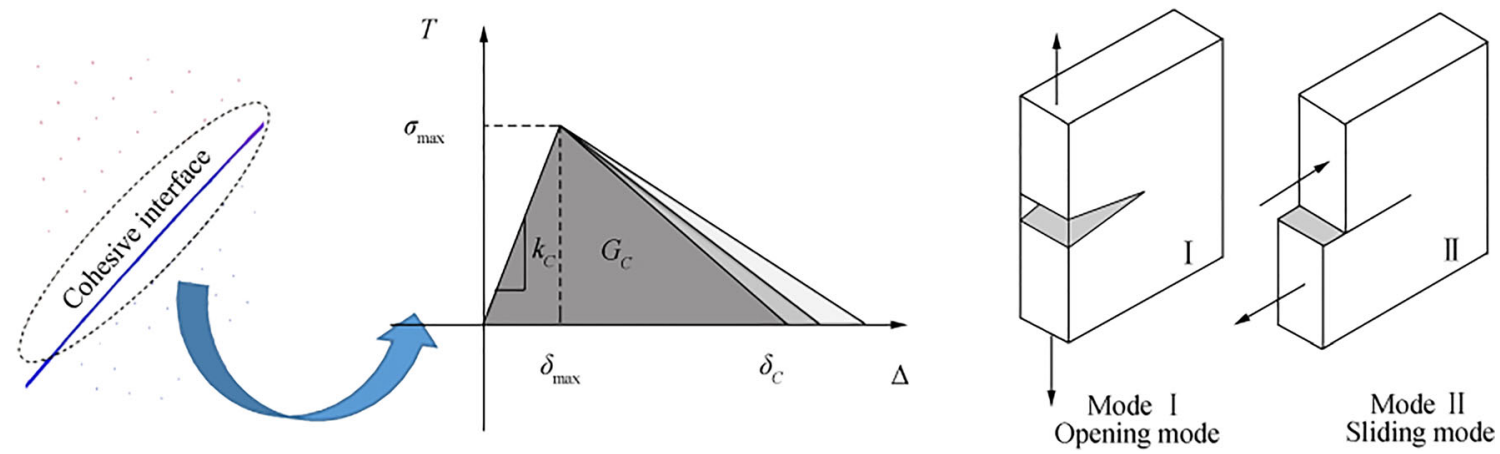

Figure 2 Cohesive element description and definition of its properties

- The "penalty stiffness," representing the steepness of the initial linear part of the law, whose influence is often found negligible, in terms of mechanical behavior.

- The peak stress, representing the strength of the bonding, defined as the apex of the triangle in Figure 2.

- The energy release rate, expressed as the area of the triangle, which is usually the most important among the cited parameters.

In general, cohesive models currently represent a powerful instrument to investigate the influence of cohesive parameters in small-scale model, while their implementation in largescale design is still far from being achieved due to computational limits. Some promising applications include the analysis of local problems, as well as the numerical characterization of the material capacity to resist against delaminating stresses as reported by Cricrì and Perrella (2017) and Woo et al. (2013).

Finally, delaminations originating at "free edges" involve very complex three-dimensional stress descriptions, as they are originated by axial stresses normal to the composite plane due to the variation of the interlaminar shear stress, which as to equal 0 when approaching the free edge. Such stress distribution leads to Mode I openings, which is often critical as bonding properties of matrix are quite poor towards such failure mode, as showed in Figure 3 (Lorriot et al. 2003). An analysis method for the computation of the threedimensional stress fields in cylindrically curved symmetric or unsymmetric cross-ply laminated shells under bending load is discussed by Kappel and Mittelstedt (2020).

Another limitation to current methods is that characterizing the composite stiffness properties, from experiments, out of the composite plane still represents a challenging task. Such properties become necessary for conducting numerical analysis adopting solid "brick" elements, which is a current requirement for cohesive analyses. Some pioneer experiments (Zimmermann et al. 2010) are being conducted on thick specimens to account for such complex properties (i.e., $G_{13}, G_{23}$, $v_{13}, v_{23}$ ) but the complexity of the experimental setup along with the high cost related to the manufacturing of specimens still limit this important characterization. However, it is worth noting that for thick plates nonlinear theories take in account the effect the distribution of stresses across the thickness; e.g., Mantari and Guedes Soares (2013) presented a generalized higher order shear deformation theory (HSDT) that accounts for nonlinear and constant variation of in-plane and transverse displacement respectively through the plate thickness.

A recent work presented some interesting experimental vs. numerical benchmarks (Moheimani et al. 2020) referring also
Figure 3 Free edge delamination mechanism, as reported by Lorriot et al. (2003)

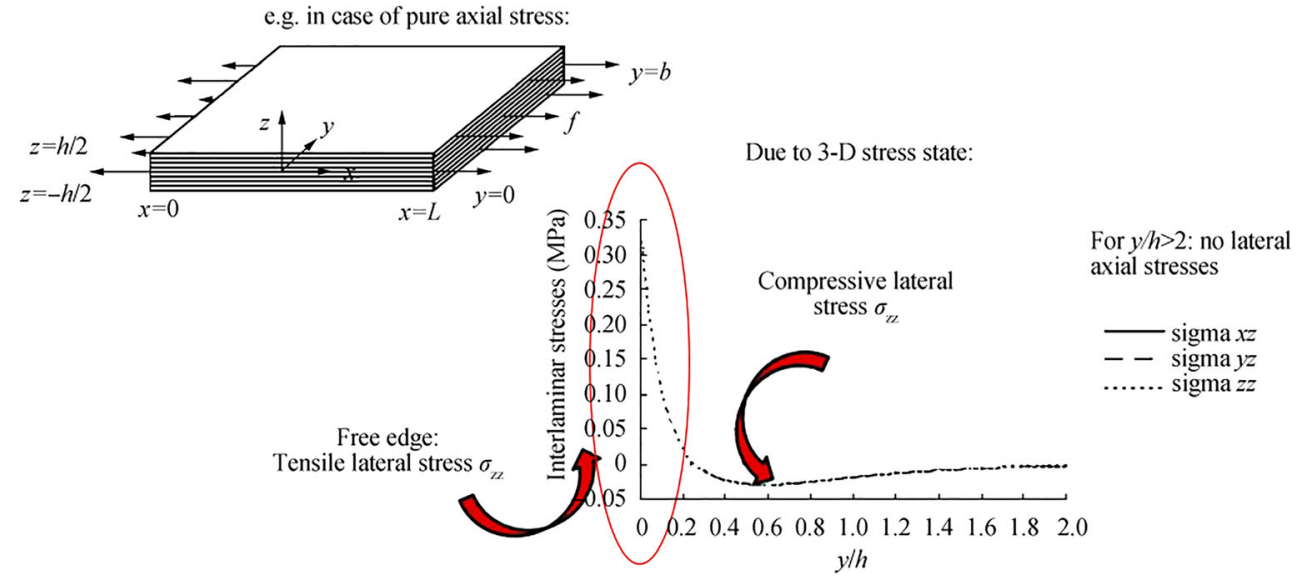

interlaminar lateral axial stresses $\left(\sigma_{p}\right)$ in the middle of the laminate versus $y$ 
earlier studies about cohesive models and FEM modeling strategies. By using user-defined cohesive mesoscale models in simulation, the local and global buckling of the face-sheets of a sandwich laminate can be precisely detected and response of sandwich structure becomes mesh independent, while mesh size is reduced. Fracture propagation can be also assessed.

Summarizing, marine composites can be designed according to three levels of complexity:

1 Simplified isotropic models, which is the current practice of most construction rules currently applied by shipyards and classification societies. This implies high safety factors but allows quick computations.

2 Multi-layered orthotropic models (analytical or numerical). This theory allows the capability of fully evaluating the stress tensor of each ply, and checking its strength towards admissible limits, when strength data are available. Such strategy is currently not ruled by any classification society for marine composites, although several societies leave this possibility to the sole responsibility of the designer.

3 Multi-layered orthotropic plies connected by cohesive interfaces. This is the current state of the art in numerical predictions. Computational efforts still represent a challenging task for the assessment of such method. Moreover, cohesive parameters present complex calibration efforts, often related to widespread experimental campaigns.

\section{Fire Resistance}

Another critical aspect arising when adopting composite materials in commercial applications is the fact that composites are, according to the International Maritime Organization (2009), combustible materials. As a consequence, fire safety has to be investigated. Understandably, fire can be considered an accidental limit state, hence strict rules on this topic were taken into account by classification societies.

Thermal degradation of organic matrix represents the main issue, when composites are exposed to high temperatures. When degrading, gases produced are highly inflammable leading to the spread of the flame front. Their ignition rises the temperature locally, accelerating the process. In fact, the International Maritime Organization bases the definition of "combustible material" on the temperature gradient measured, when a purposely made specimen is exposed to a certain temperature. The composite under investigation is exposed for $20 \mathrm{~min}$ at a temperature of $750{ }^{\circ} \mathrm{C}$, if its weight loss is less than $50 \%$ and its temperature below $800{ }^{\circ} \mathrm{C}$ the material is classified as "non-combustible." If the former prescription can be easily satisfied when glass content is greater than 0.5 , the latter condition results very strict, due to the heat produced by the ignition of gases produced by thermal degradation. Relevant published works include Hertzberg and HedlundÅström (2010), Evegren et al. (2014), and Evegren and Hertzberg (2017).

Current researches focus on flame retardant additives: hybrids of aluminum hypophosphite and ammonium polyphosphate proved to be very effective by Lin et al. (2016), as well as phosphorus-containing star-shaped flame retardant included in the polyester matrix as tested by Bai et al. (2014).

Traditionally, earlier research found effective retarding agents for polyester matrix, however such additives used to have a heavy negative impact on the matrix mechanical properties and the cited works did not focus on the mechanical aspect. From this aspect, an experimental work by Saat et al. (2017) tested the influence on mechanical properties of aluminum phosphate, used as fire retardant in fiberglass-reinforced polyester matrix for leisure boat applications, indicating promising results.

Another aspect to be analyzed is the one related to the work by Rahm et al. (2017), who studied the structural fire integrity of lightweight multiple core sandwich structures, aimed to demonstrate that steel can be replaced by fiber-reinforced polymer (FRP) sandwich panels, obtaining significant weight savings. More in detail, they presented results from vertically loaded fire resistance tests of two structures and show that the multiple core sandwich bulkhead demonstrated structural fire integrity performance well beyond $60 \mathrm{~min}$ while having a significantly lower structural weight and thickness. The new type of multiple core sandwich structure thus provides great potential, both from a weight saving and a fire safety perspective.

\section{Current Technological Practice: Manufacturing Methods}

Composite materials specifications sometimes differ from their designed ones since some defects, such as manufacturing defects, cause them to deviate from the expected enhancement in mechanical properties. These manufacturing defects involve misalignment, waviness, fiber/matrix debonding, delamination, and formation of voids in the matrix. In particular, voids lead to early failure of the voided regions and eventually to overall failure of the composite at lower ultimate stress levels than to be expected, but this can be avoided by manipulating some manufacturing processes parameters (Mehdikhani et al. 2018). It is therefore needed to analyze different types of composite manufacturing techniques to understand which one will ensure the optimal strength.

The current manufacturing methods for large marine structures includes hand lay-up lamination and vacuum bag 
infusion. Other methods like prepregs, resin transfer molding, filament winding, etc. are restrained to small hulls or components due to their high cost and technological complexity.

Hand lay-up lamination consists on manually impregnating the fiber plies and place them on the mold, the stacking sequence is then consolidated in order to improve fiber alignment and uniformly distribute the resin. The sequence of operations must be completed within the resin working time as the inhibitor, which is present in the resin solution, prevent the free radicals from being available to the curing reaction. This method is highly influenced by the ability of the operator to correctly impregnate the fibers and by technological features such as textile parameters, which play a non-negligible role in the laminate permeability as shown by Grössing et al. (2016). Good permeability prevents dry areas, that would result into fiber-matrix de-cohesions, or embedded delaminations. The uniform distribution of the resin and the correct fiber/resin ratio helps providing constant mechanical properties. The presence of air bubbles of various size is also common in this manufacturing method: the spherical shape of the bubbles make them less critical than sharp de-cohesions originating from impregnability issues, in terms of stress concentration, although they can influence the interlaminar shear strength up to $25 \%$ as investigated by Di Landro et al. (2017) and Godani et al. (2014). Shipyards are gradually abandoning the manual impregnation, which is still very common indeed, in favor to the impregnation machines.

Impregnation machines are able to provide uniform and constant resin content to the wetted laminates, limiting the human influence on this critical parameter, moreover, the impregnation machine is usually hanged above the mold, thus easing the plies positioning, speeding-up the construction (Figure 4).

In vacuum bag manufacturing method, the dry fibers are arranged on the mold an and airtight bag is placed on top. Adhesive tape is used to seal possible holes and a vacuum pump extracts the air from inside the bag. Opposite to the vacuum pump, a number of resin inlets are positioned to let the resin flow into the bag. This method increases the

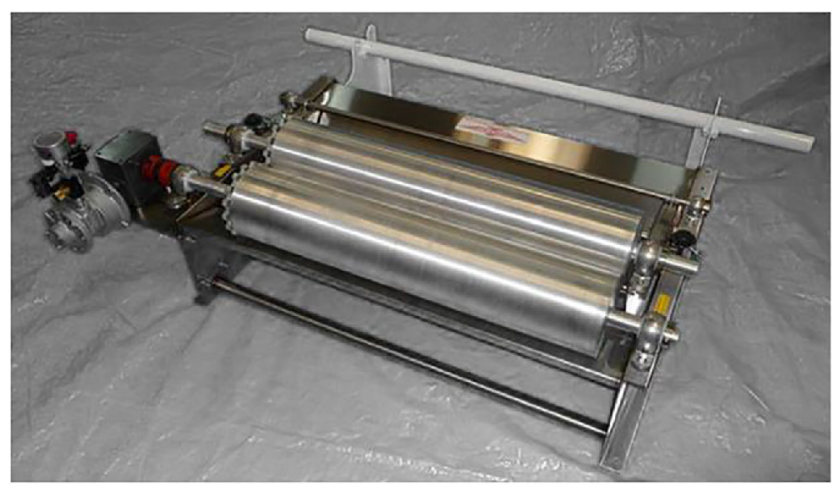

Figure 4 Impregnating machine for fiberglass products (Phoenix equipment, www.phoenixequipment.com) composite quality limiting the manufacturing induced imperfections, moreover, the fiber content is also improved as less resin is necessary to correctly impregnate an identical stacking sequence, compared with manual lay-up. A study of the influence of vacuum level on fiber fraction and flexural properties has been completed using burn-off and three-point bending tests (Alizadeh et al. 2016). Besides the higher manufacturing cost involved in this method, some critical technological and mechanical aspects have to be discussed as they are not sufficiently addressed in any regulation nor in scientific and technical literature despite their significance. Truth to tell, shipyards and composite manufacturers are well aware of the problem and empirically solve the issues during lamination.

The former is related to the exothermic peak during the curing stage, as both polyester and epoxy matrices are characterized by exothermic curing reaction. The exothermic peak is the maximum temperature reached by the composite while curing: if the exothermic peak is too high, permanent deformations may affect the laminate (in extreme cases the matrix can also combust), as the fibers expand when heated by the liquid resin and are restrained by the solid matrix when the temperature decreases. On the contrary, if the exothermic peak is too low lack, of polymerization will affect the matrix, resulting into insufficient hardness. Depending on the resin type, fixed ranges for the exothermic peak apply (usually $50^{\circ}$ to $55^{\circ} \mathrm{C}$ for most polyester resins). The peak mainly depends on the resin exothermic process, which is a fixed parameter once the matrix is chosen, as recently investigated by Vargas et al. (2015) for polyester and Park et al. for epoxy (2015). Other governing parameters are the ambient temperature, which can seldom be controlled in shipyards, especially when laminating outdoor, and mostly the laminate thickness, as thicker laminates produce higher exothermic peaks since the heat transfer to the environment is less efficient.

This aspect results in the need of splitting the lamination of thick stacking sequences into multiple stages, waiting for the cure of the partial laminate before continuing laminating. The hand lay-up manufacturing method is not that sensitive towards this aspect: it is sufficient to wait for the cure of the partial stacking sequence, then laminating over the remaining layers that will bond together with chemical adhesion, taking advantage on chemical features that characterize surfaces in polyester resin exposed to the air, when built in hand lay-up. Infusion methods instead requires expensive consumables that have to be disposed after the process, hence splitting the lamination into different stages to reduce the exothermic peak significantly increases the manufacturing cost. Moreover, the cured surfaces will not bond over fresh resin by chemical adhesion, but only mechanical adhesion will be possible, and this will require surface treatments. The possibility of chemical adhesion over cured laminates will be discussed in the next section of the paper. 
For this reason, in naval applications (e.g., minehunters), shipyards still prefer to build thick laminates with traditional hand lay-up methods, limiting the vacuum infusion to decks, superstructures and components. In leisure boat industry, the thickness involved are usually not critical in term of exothermic peak, even in the bottom shell, and the manufacturing method choice is governed by a cost-benefit analysis (Astrom 1997).

Another non-negligible mechanical aspect related to the manufacturing method is the bending response of the produced composite. It was previously mentioned that infusionmade composites obviously present better quality towards embedded imperfection such as de-cohesions, air inclusions and delaminations, that can lead to early failure due to stress concentration and fracture propagation, or progressive damaging due to load cycles. Moreover, the higher fiber content associated to the infusion method leads to higher specific mechanical properties on the one hand, although the lower thickness induces a diminished bending response on the other. This aspect can easily be proven by calculating the mechanical properties deriving from empirical formulations provided by classification societies rules: if from one side the higher fiber content leads to a higher material stiffness, the lower thickness leads to a loss of inertial contribution. The resulting laminate will show a reduced bending response, and this assumption has found experimental evidence in Yaacob et al. (2017), where a small 12 -ft fishing boat was built by both hand layup and infusion, with identical stacking sequence. Specimens were cut out and tested in accordance to the standard ASTM D3039, D3039M, ASTM D695-02a and ASTM D790-07. The experiments showed that the resin infusion technique produced better result upon ultimate tensile strength $(+27 \%)$ but slightly less satisfactory for in compressive stress $(-12 \%)$ and flexural stress $(-34 \%)$.

The thickness reduction also gives rise to concerns about elastic stability, which is mainly governed by bending and torsional stiffness of the laminate. In conclusion, the potential benefits produced by infusion method rather than hand lay-up lamination are out of discussion and well assessed in terms of composite quality. However, the reduced thickness led by such manufacturing method has to be considered in the design stage: if a stacking sequence produced in hand lay-up methods satisfies the design requirements, the same sequence may not be satisfactory if manufactured by infusion, and reinforcement plies shall be added.

Prepregs represent the most recent state of the art in terms of composite performance, as they can maximize the fiber content leading to outstanding material properties. The extremely high cost and the need for refrigerated storage rooms limit their application to racing yachts and high-performance components. Manufacturing cost of prepreg is also a critical aspect, as to achieve outstanding material performances vacuum bag technology in controlled environment shall be adopted. Godani et al. (2015) highlighted poor interlaminar performances of prepregs with fabrication induced imperfection with respect to a similar fiberglass-reinforced composite produced by infusion. It is worth noting that the specimens were cut out from laminates produced for actual industrial applications. Gangloff et al. (2017) showed that imperfections related to air inclusion mainly originate in prepreg production, while the curing process inside the vacuum bag has a scarce influence on the overall quality.

\section{Recent Technological Innovations}

Innovation in polyester matrix, with the introduction of the vinyl ester one in particular, made available on the market matrices characterized by outstanding performances in terms of elongation at break (above $6 \%$ and more), as well as interlaminar adhesion. This aspect plays a key role in the production of marine composites, since it closed the gap with epoxy resin, considered the top performing matrix.

Besides the higher cost of epoxy, it is also worth noting that correct handling of an epoxy matrix is a challenging task for large marine composite applications, as epoxy requires fixed thermal profiles in the post-curing stage, in order to show clear advantages with respect to a vinyl ester matrix in term of performances. Hüther and Brøndsted (2016) found that fatigue performance of unidirectional glass fiber-reinforced epoxy composites, for loading at $0^{\circ}$ with respect to fiber orientation, is highly influenced by the curing cycle. Thus, relatively small components can be built in pressurized ovens, while large hulls require mold heating. In conclusion, the handling difficulties are still limiting the widespread use of epoxy for large marine structures mainly to racing yachts and naval applications.

On the other hand, epoxy matrix does not contain styrene, which is a volatile toxic component of polyester resins. Hence, the risk for the personnel to be exposed to a potential lifethreatening substance is reduced, although epoxy also present some human health issues related to the presence of bisphenol-A, which is a recognized endocrine disruptor.

Another innovation related to reinforcing fiber were led by the introduction of the stitched fibers or non-crimp fabrics, that are able to maintain the planarity of the reinforcement. The benefit of non-crimp fabrics leads to an increment of the tensile ultimate strength of about 20 to $30 \%$, being equal the glass content with respect to a woven fabric, according to an investigation conducted by the author upon reinforcements currently available on the market. Moreover, the lower number of interstitial spaces between non-crimp fibers also allows an increment in the composite fiber content, leading to a further improvement in terms of material properties. On the other hand, noncrimp fibers are more expensive than traditional woven 
roving, thus their application is limited to highperformance composites. Another critical aspect was highlighted by Shiino et al. (2017) in delamination problems, which found a decrease in the surface propagation energy because the stitch yarn replaced the carbon fiber/ epoxy interface, which has better chemical affinities.

\section{Joining of Composites}

Joining of fiber-reinforced plastic can be achieved by surface bonding, bolted connection or combined solution.

Bonding of composites is an important aspect of composite production, as delamination of top-hat stiffeners is a typical failure mode for marine structures as shown by Raju et al. (2013), in particular when subjected to impact loading (Ji et al. 2016).

Top-hat stiffeners can be infused together with the hull shell or laminated at different stages: if the reinforcements are laminated on a previously cured shell, the adhesion must be checked. Other bonding problems include hulldeck connection and bulkheads-hull connection. Bonding on composite surfaces can be achieved by chemical adhesion or mechanical adhesion. The effectiveness of the bonding, namely the delamination strength and the energy release rate, is not influenced by the nature of the adhesion, namely chemical or mechanical, in general. Moreover, preparing a cured surface for mechanical adhesion requires treatments to increase surface roughness, thus extending the production time. In addition, the joining of these materials is very sensitive, in terms of strength, to many factors including the just mentioned surface preparation, adhesive choice, application methods and cleaning conditions. Statistical experimental design techniques (DOE) have been used by Sutherland et al. (2019) to study the multi-parameter problem of the bonding of composite materials through a large test program on " $T$ "-joints representative of various joints used to fabricate marine composite structures. The effects of different surface preparation, cleaning methods and adhesives, along with the interactions between these effects, were therefore investigated.

For large engineering structures in fact, composite joints between plates, stiffeners and other sub components are often post-cured due to the scale of the production process and typical interfaces contain a chopped strand mat (CSM) layer. Debonding of sub-component parts is a common failure mode of these types of structures, however the characterization of these typical post-cured interfaces is not well understood (Yetman et al. 2019).

The mode I and mode II fracture properties for co-cured and post-cured joints are assessed and compared in the work of Yetman et al. (2017) by providing a full characterization of typical materials with a complete data set for both co-cured interfaces, typical of mid-laminate debonds, and post-cured interfaces, typical of sub-component joints.

A favorable condition, which only occurs for polyester matrices produced by hand lay-up on air exposed surfaces, allow chemical adhesion without any surface treatment required, for a certain time after curing. The phenomenon is due to the fact that styrene evaporation on the air exposed surface results in a non-stoichiometric polyester-styrene ratio, leaving some polyester groups free to bond to styrene once the liquid matrix comes into contact with the cured surface. Secondarily, the oxygen present in the air is a strong inhibitor of the curing reaction, leaving the external molecular layer under-polymerized.

Joining of composites to other materials has also become a challenging topic in recent years. Technological restrictions are the main factor limiting hull composites in size, although the lack of stiffness of fiberglass-reinforced plastics represents another issue against hull-girder primary stresses, that grow together with the ship's length. In view of the above, large hulls are still built in steel or aluminum alloy except for some naval vessels, although composites provide advantages for superstructure and components (see Figure 5).

Composite Superstructure Concept (CSC) is a joint venture of companies heavily involved in the Swedish governmentfunded LASS project (2004-2008), and member of the E-Lass (the European network for lightweight applications at sea), established in 2013, that gather stakeholders interested in lightweight design for the maritime industry. According to CSC, key benefits introduced by composite superstructures include: significant weight saving, increased payloads, builtin thermal insulation, reduced fuel consumption, increased stability, lower through-life cost, compound curves readily achieved. Promising application areas of composites are as

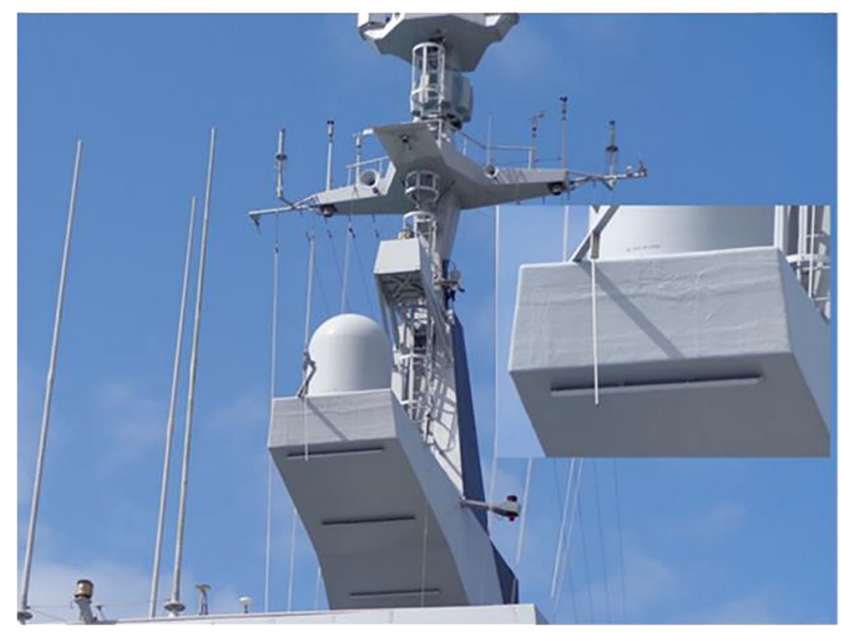

Figure 5 Naval ship top mast built up in fiberglass composite 
follows: superstructures, deck houses, balconies, architectural features, funnels, shelters, cargo hatches, masts.

The steel to composite bonding for marine applications and, in particular, the joint strength/failure modes prediction, has been widely characterized by experimental/numerical activities in recent years by Ribeiro et al. (2016), Li et al. (2015), Senguttuvan and Lillymercy (2015) and Son et al. (2014) among the others. In particular, in very recent years Kharghani and Guedes Soares $(2018 \mathrm{a}, \mathrm{b})$ tested a large-scale model of a composite-to-steel hybrid balcony overhang (Figure 6) to find its strength and stiffness under imposed shear and bending loads. The configuration tested was representative of a solution being considered for the balconies of cruise ships, where the substitution of steel by composites aims at weight saving.

Cohesive models also found application in predicting lap joints behavior: Tomaso et al. (2014) successfully predicted the progressive failure and local strains with a

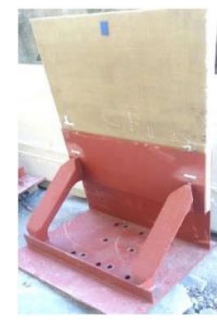

(a)

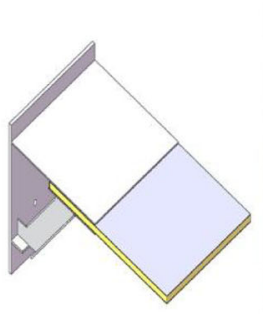

(b)

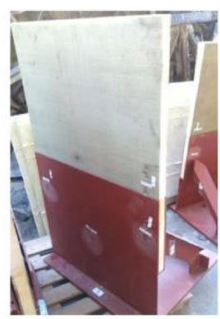

(c)

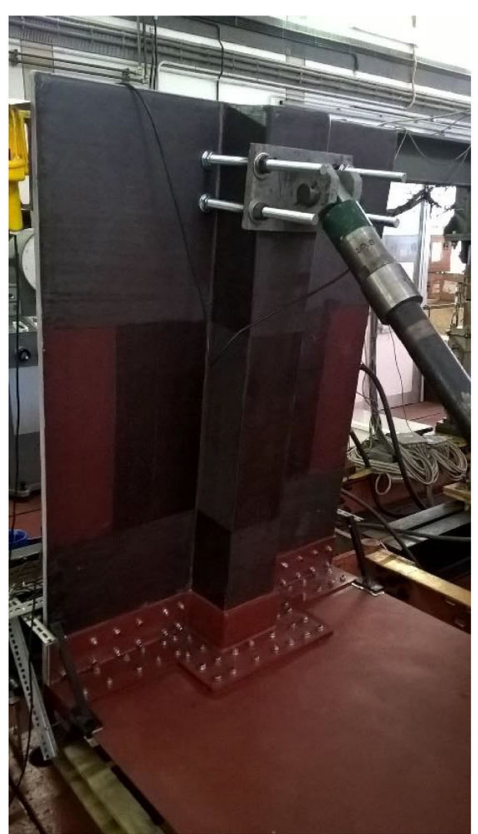

(e)

Figure 6 Strength tests of hybrid joints, large-scale specimens top (from Kharghani and Guedes Soares 2018a): (a) Large-scale test specimen of hybrid joint. (b) Detail of test specimen. (c) Back side of test
2D solid numerical model with plane-strain theory, for a steel to composite joint experimentally tested. Local 3D solid models can be easily investigated by numerical strategies with reasonable computational efforts, while modeling global structural models still represent a challenging computational task.

Steel to composite bonding is also being considered as an efficient repairing strategy of degraded and corroded ship structures. Such technique is already well assessed in civil engineering.

Potential advantages led by composite materials were also investigated by government-funded Pyxis project, where different materials for a naval ship mast able to integrate most of the instrumentation and sensors typical of a Combat System (radar, communications, electronic warfare) were compared. Gaiotti et al. (2018) conducted experiments on the bonded/bolted connection between the mast and the steel deck.

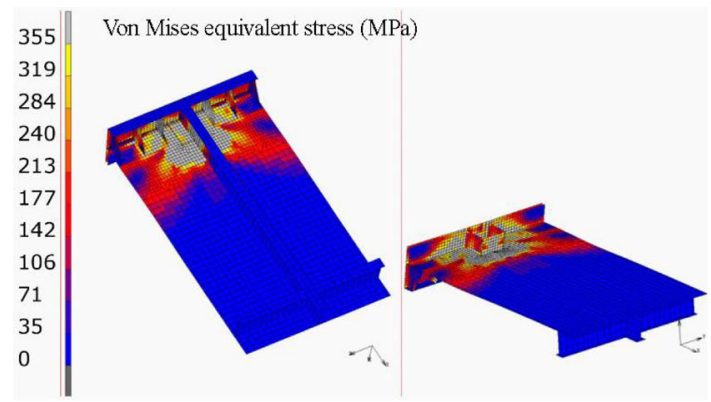

(d)

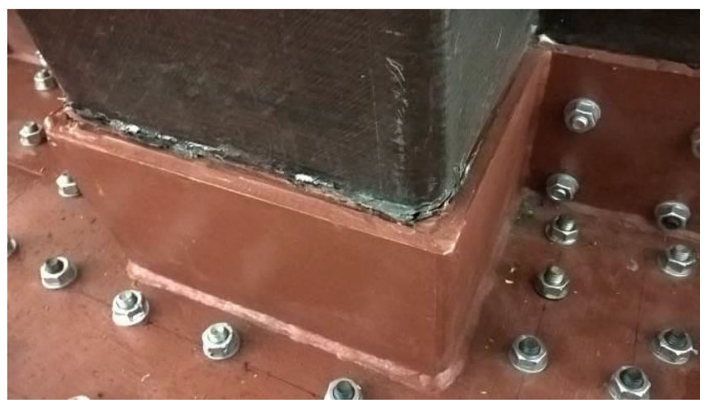

(f)

specimenBottom bottom (from Gaiotti et al. 2018): (d) FEM analysis of bonded-bolted joint specimen. (e) Bonded-bolted joint specimen. (f) Detail of the joint after collapse test 


\section{Conclusions}

This work presented the current industrial state of the art of marine composites, in terms of design approaches, rule requirements and manufacturing processes. The work is aimed at filling the gap between modern advances in powerful computation tools, able to describe complex failure modes, and current design ways and means, too often limited to quasiisotropic, bi-dimensional approximations. Knowledge and efficient technological transfers are essential to fill the current gap between research centers and universities on one side, and designers and shipbuilders on the other.

Up-to-date computation tools availability and related theoretical knowledge allow introducing within the shipbuilding industry a new perspective in applying composite materials and exploiting their potential advantages. However, design processes and scantling assessment approaches currently applied by designers in shipyards everyday practice shall be substantially modified, overcoming the empirically driven approach based on admissible stresses and rule requirements and leading towards a much more design oriented and transparent limit state design approach.

To this aim, first engineering principles, structural mechanics and numerical methods, i.e., FEM, need appropriate implementations, making their use more straightforward, as well as more comprehensive material characterization providing substantial input data to them. In short, direct calculations shall be more widely used. Literature review presented in this paper shows that many scantling assessment and structural analysis methods are already available and only need to be more and more applied and included in standards and practice. Material characterization data are partially available but they will likely follow the trend according to industry needs.

Manufacturing processes are instead more sensitive towards industrial innovation: e.g., improvements on vacuum bag techniques are nowadays applied on a daily basis, and new fabrics, as non-crimp fibers, are constantly available on the market and quickly implemented in the production stage. However, full understanding of the effect of construction and fabrication methods and of the corresponding induced imperfections on the fabricated structure is much more difficult to assess and characterize. And even more difficult is to make such information openly available and included in rules and standards. A few papers have been mentioned in the present literature review, highlighting that industry trend is in this direction and efforts are ongoing. However, it appears that, for the time being, obtained results are related to research activities and still need to be transferred into design and construction practice.

Funding Open access funding provided by Università degli Studi di Genova within the CRUI-CARE Agreement.
Open Access This article is licensed under a Creative Commons Attribution 4.0 International License, which permits use, sharing, adaptation, distribution and reproduction in any medium or format, as long as you give appropriate credit to the original author(s) and the source, provide a link to the Creative Commons licence, and indicate if changes were made. The images or other third party material in this article are included in the article's Creative Commons licence, unless indicated otherwise in a credit line to the material. If material is not included in the article's Creative Commons licence and your intended use is not permitted by statutory regulation or exceeds the permitted use, you will need to obtain permission directly from the copyright holder. To view a copy of this licence, visit http://creativecommons.org/licenses/by/4.0/.

\section{References}

Airoldi A, Baldi A, Bettini P, Sala G (2015) Efficient modelling of forces and local strain evolution during delamination of composite laminates. Compos Part B 72:137-149. https://doi.org/10.1016/j. compositesb.2014.12.002

Alizadeh F, Guedes Soares C (2019) Experimental and numerical investigation of the fracture toughness of glass/vinylester composite laminates. Eur J Mech A Solids 73:204-211. https://doi.org/10.1016/j. euromechsol.2018.08.003

Alizadeh F, Sutherland LS, Guedes Soares C (2016) Effect of vacuum bag pressure on the flexural properties of GFRP composite laminates. In: Guedes Soares C, Santos TA (eds) Maritime technology and engineering. Taylor \& Francis Group, London, pp 429-434

Andideh M, Esfandeh M (2017) Effect of surface modification of electrochemically oxidized carbon fibers by grafting hydroxyl and amine functionalized hyperbranched polyurethanes on interlaminar shear strength of epoxy composites. Carbon 123:233-242. https:// doi.org/10.1016/j.carbon.2017.07.035

Astrom BT (1997) Manufacturing of polymer composites. CRC press

Bai Z, Song L, Hu Y, Gong X, Yuen RKK (2014) Investigation on flame retardancy, combustion and pyrolysis behavior of flame retarded unsaturated polyester resin with a star-shaped phosphorus-containing compound. J Anal Appl Pyrolysis 105:317-326. https://doi.org/ 10.1016/j.jaap.2013.11.019

Bert CW (1989) Classical lamination theory. In: Pendleton RL, Tuttle ME (eds) Manual on experimental methods for mechanical testing of composites. Springer, Dordrecht. https://doi.org/10.1007/978-94009-1129-1_3

Colombo C, Vergani L (2014) Influence of delamination on fatigue properties of a fibreglass composite. Compos Struct 107(1):325-333. https://doi.org/10.1016/j.compstruct.2013.07.028

Cricrì G, Perrella M (2017) Investigation of mode III fracture behaviour in bonded pultruded GFRP composite joints. Compos Part B 112: 176-184. https://doi.org/10.1016/j.compositesb.2016.12.052

Di Landro L, Montalto A, Bettini P, Guerra S, Montagnoli F, Rigamonti $M$ (2017) Detection of voids in carbon/epoxy laminates and their influence on mechanical properties. Polym Polym Compos 25(5): 371-380. https://doi.org/10.1177/096739111702500506

Evegren F, Hertzberg T (2017) Fire safety regulations and performance of fibre-reinforced polymer composite ship structures. Proc Inst Mech Eng M J Eng Mar Environ 231(1):46-56. https://doi.org/10.1177/ 1475090215620449

Evegren F, Rahm M, Arvidson M, Hertzberg T (2014) Fire testing of external combustible ship surfaces. Fire Saf Sci 11:905-918. https:// doi.org/10.3801/IAFSS.FSS.11-905

Gaiotti M, Rizzo CM, Branner K, Berring P (2014) An high order mixed interpolation tensorial components (MITC) shell element approach for modeling the buckling behavior of delaminated composites. 
Compos Struct 108(1):657-666. https://doi.org/10.1016/j. compstruct.2013.10.003

Gaiotti M, Ravina E, Rizzo CM, Ungaro A (2018). Testing and simulation of a bolted and bonded joint between steel deck and composite side shell plating of a naval vessel. Eng Struct 172:228-238. https:// doi.org/10.1016/j.engstruct.2018.06.008

Gaiotti M, Zamarin A, Josefson BL, Matulja T (2020) A numerical sensitivity analysis on the cohesive parameters of a carbon-steel single lap joint. Ocean Eng 198:art. no. 106010. https://doi.org/10.1016/j. oceaneng.2019.04.091

Gangloff JJ Jr, Cender TA, Eskizeybek V, Simacek P, Advani SG (2017) Entrapment and venting of bubbles during vacuum bag prepreg processing. J Compos Mater 51(19):2757-2768. https://doi.org/10. 1177/0021998316676325

Ghelardi S, Gaiotti M, Rizzo CM (2015) On the shear lag effective breadth concept for composite hull structures. Ships Offshore Struct 10(3):272-289. https://doi.org/10.1080/17445302.2014. 887172

Godani M, Gaiotti M, Rizzo CM (2014) Interlaminar shear strength of marine composite laminates: tests and numerical simulations. Compos Struct 112:122-133. https://doi.org/10.1016/j.compstruct. 2014.02.013

Godani M, Gaiotti M, Rizzo CM (2015) Influence of air inclusions on marine composites inter-laminar shear strength. International Offshore and Polar Engineering Conference, Kona, Hawaii, USA, 593-601. ISBN: 978-1-880653-89-0

Goodship V, Middleton B, Cherrington R (2016) Design and manufacture of plastic components for multifunctionality - structural composites, injection molding, and 3D printing. Elsevier. Composites: manufacture and application, 53-101. https://doi.org/10.1016/ B978-0-323-34061-8.00003-X

Gowayed (2013) Developments in fiber-reinforced polymer (FRP) composites for civil engineering. Woodhead Publishing Series in Civil and Structural Engineering, Nasim U Eds. Types of fiber and fiber arrangement in fiber-reinforced polymer (FRP) composites, 3-17. https://doi.org/10.1533/9780857098955.1.3

Grössing H, Fauster E, Weninger M, Schledjewski R (2016) Influence of textile parameters on the in-plane permeability characteristics of non-crimped fabric preforms. Polym Compos 37(6):1854-1863. https://doi.org/10.1002/pc.23360

Halpin JC, Kardos JL (1976) The Halpin-Tsai equations: a review. Polym Eng Sci 16(5):344-352. https://doi.org/10.1002/pen.760160512

Hertzberg T, Hedlund-Åström A (2010) The composite superstructure concept. RINA, Royal Institution of naval architects - Ship Design and Operation for Environmental Sustainability, London, United Kingdom, 17-25

Hüther J, Brøndsted P (2016) Influence of the curing cycles on the fatigue performance of unidirectional glass fiber reinforced epoxy composites. IOP Conf Ser Mater Sci Eng 139(1):012023. https://doi.org/10. 1088/1757-899X/139/1/012023

IMO International Maritime Organization (2000) International code of safety for high-speed craft (HSC code). IMO resolution MSC97(73)

International Maritime Organization (IMO). IMO Resolution A.1023(26), 2009. Code for the Construction and Equipment of Mobile Offshore Drilling Units (2009 MODU Code)

Ji Z, Guan Z, Li Z (2016) Damage resistance property of stiffened composite panels under low-velocity impact. Beijing Hangkong Hangtian Daxue Xuebao 42(4):751-761. https://doi.org/10.13700/ j.bh.1001-5965.2015.0261

Jones RM (1998) Mechanics of composite materials. Materials Science \& Engineering Series, 2nd edn. CRC Press

Kaddour AS, Hinton MJ, Li S, Smith PA (2014) The World-Wide Failure Exercise: how can composites design and manufacture communities build their strength. ECCM 16- 16th European Conference on Composite Materials, Seville, Spain, 22-26 June 2014
Kalantari M, Dong C, Davies IJ (2017) Effect of matrix voids, fibre misalignment and thickness variation on multi-objective robust optimization of carbon/glass fibre-reinforced hybrid composites under flexural loading. Compos Part B 123:136-147. https://doi.org/10. 1016/j.compositesb.2017.05.022

Kappel A, Mittelstedt C (2020) Free-edge stress fields in cylindrically curved cross-ply laminated shells. Compos B Eng:183. https://doi. org/10.1016/j.compositesb.2019.107693

Kharghani N, Guedes Soares C (2016) Effect of uncertainty in the geometry and material properties on the post-buckling behavior of a composite laminate. Guedes Soares, C. \& Santos T. A., (eds.). Maritime technology and engineering 3. London, Taylor \& Francis Group, p 497-503

Kharghani N, Guedes Soares C (2018a) Experimental and numerical study of hybrid steel-FRP balcony overhang of ships under shear and bending. Mar Struct 60:15-33. https://doi.org/10.1016/j. marstruc. 2018.03.003

Kharghani N, Guedes Soares C (2018b) Experimental, numerical and analytical study of bending of rectangular composite laminates. Eur J Mech A Solids 72:155-174. https://doi.org/10.1016/j. euromechsol.2018.05.007

Kharghani N, Guedes Soares C (2019) Analytical and experimental study of the ultimate strength of delaminated composite laminates under compressive loading. Compos Struct 228:111355. https://doi.org/ 10.1016/j.compstruct.2019.111355

Kharghani N, Guedes Soares C (2020) Experimental, numerical and analytical study of buckling of rectangular composite laminates. Eur J Mech A Solids 79:103869. https://doi.org/10.1016/j.euromechsol. 2019.103869

Kim S-Y, Shim CS, Sturtevant C, Kim DD-W, Song HC (2014) Mechanical properties and production quality of hand-layup and vacuum infusion processed hybrid composite materials for GFRP marine structures. Int J Nav Architect Ocean Eng 6(3):723-736. https://doi.org/10.2478/IJNAOE-2013-0208

Kobayashi S, Tsukada T, Morimoto T (2017) Resin impregnation behavior in carbon fiber reinforced polyamide 6 composite: effects of yarn thickness, fabric lamination and sizing agent. Compos A: Appl Sci Manuf 101:283-289. https://doi.org/10.1016/j.compositesa.2017. 06.030

Li X, Li P, Lin Z, Yang D (2015) Mechanical behavior of a glass-fiber reinforced composite to steel joint for ships. J Mar Sci Appl 14(1): 39-45. https://doi.org/10.1007/s11804-015-1296-8

Li H, Yao Y, Guo L, Zhang Q, Wang B (2018) The effects of delamination deficiencies on compressive mechanical properties of reinforced composite skin structures. Compos Part B 155:138-147. https://doi.org/10.1016/j.compositesb.2018.08.034

Lin Y, Jiang S, Hu Y, Chen G, Shi X, Peng X (2016) Hybrids of aluminum hypophosphite and ammonium polyphosphate: highly effective flame retardant system for unsaturated polyester resin. Polym Compos 39(5):1763-1770. https://doi.org/10.1002/pc.24128

Lorriot TH, Marion G, Harry R, Wargnier H (2003) Onset of free-edge delamination in composite laminates under tensile loading. Compos Part B 34(5):459-471. https://doi.org/10.1016/S1359-8368(03)00016-7

Ma L, Liu D (2016) Delamination and fiber-bridging damage analysis of angle-ply laminates subjected to transverse loading. J Compos Mater 50(22):3063-3075. https://doi.org/10.1177/ 0021998315615647

Maggiani G, Boote D, Gaggero T, Gaiotti M, Rizzo CM (2017) Influence of air inclusions on marine composites inter-laminar shear strength. 2017 International Ocean and Polar Engineering Conference, San Francisco, CA, USA, June 25-30

Mantari JL, Guedes Soares C (2013) Finite element formulation of a generalized higher order shear deformation theory for advanced composite plates. Compos Struct 96:545-553

Mehdikhani M, Gorbatikh L, Verpoest I, Lomov SV (2018) Voids in fiber-reinforced polymer composites: a review on their formation, 
characteristics, and effects on mechanical performance. J Compos Mater 53:1579-1669. https://doi.org/10.1177/0021998318772152

Mohammad HR, Mousa S (2019) Finite element modeling strategies for $2 \mathrm{D}$ and $3 \mathrm{D}$ delamination propagation in composite $\mathrm{DCB}$ specimens using VCCT, CZM and XFEM approaches. Theor Appl Fract Mech 103:102246. https://doi.org/10.1016/j.tafmec.2019.102246

Moheimani R, Sarayloo R, Hamid D (2020) Failure study of fiber/epoxy composite laminate interface using cohesive multiscale model. Adv Compos Lett 29:1-19. https://doi.org/10.1177/2633366X20910157

Mouritz AP, Gellert E, Burchill P, Challis K (2001) Review of advanced composite structures for naval ships and submarines. Compos Struct 53(1):21-42. https://doi.org/10.1016/S0263-8223(00)00175-6

Olave M, Vara I, Husabiaga H, Aretxabaleta L, Lomov SV, Vandepitte D (2015) Nesting effect on the mode I fracture toughness of woven laminates. Compos A: Appl Sci Manuf 74:166-173. https://doi.org/ 10.1016/j.compositesa.2015.03.017

Park S-J, Heo G-Y, Jin F-L (2015) Cure behaviors and thermal stabilities of tetrafunctional epoxy resin toughened by polyamideimide. Macromol Res 23(4):320-324. https://doi.org/10.1007/s13233015-3051-z

Pemberton R, Summerscales J, Graham-Jones J (2019) Marine composites design and performance. Woodhead Publishing Series in Composites Science and Engineering, Materials selection for marine composites, 3 30. https://doi.org/10.1016/B978-0-08-102264-1.00001-7

Rahm M, Evergren F, Johnson E, Ringsberg JW (2017) Structural fire integrity testing of lightweight multiple core sandwich structures. In: Soares CG, Garbatov Y (eds) Progress in the analysis and design of marine structures. Taylor and Francis, London, pp 869-875

Raju, Gangadhara Prusty B, Kelly DW (2013) Delamination failure of composite top-hat stiffeners using finite element analysis. Proc Inst Mech Eng M J Eng Mar Environ 227(1):61-80. https://doi.org/10. 1177/1475090212452975

Ribeiro TEA, Campilho RDSG, da Silva LFM, Goglio L (2016) Damage analysis of composite-aluminium adhesively-bonded single-lap joints. Compos Struct 136:25-33. https://doi.org/10.1016/j. compstruct.2015.09.054

Roy Xu L, Rosakis Ares J (2002) Impact failure characteristics in sandwich structures. Part I: Basic failure mode selection. Int J Solids Struct 39:4215-4235. https://doi.org/10.1016/S0020-7683(02) 00245-7

Russo A, Zarrelli M, Sellitto A, Riccio A (2019) Fiber bridging induced toughening effects on the delamination behavior of composite stiffened panels under bending loading: a numerical/experimental study. Materials 12(15):2407. https://doi.org/10.3390/ma12152407

Saat AM, Malik AA, Azmi A, Latif MFA, Ramlee NE, Johan MR (2017) Effect of aluminum phosphate on mechanical and flame retardant properties of composites fiberglass. ARPN J Eng Appl Sci 12(4): $1315-1318$

Selvaraju S, Ilaiyavel S (2011) Applications of composites in marine industry. J Eng Res Stud II:89-91

Senguttuvan N, Lillymercy J (2015) Joint strength analysis of single lap joint in glass fiber composite material. Int J Appl Eng Res 10(7): $16535-16545$
Shenoi RA, Wellicome RF (1993) Composite materials in maritime structures. Cambridge Ocean Technology Series, Vol.1 and Vol.2

Shiino MY, Pelosi TS, Cioffi MOH, Donadon MV (2017) The role of stitch yarn on the delamination resistance in non-crimp fabric: chemical and physical interpretation. J Mater Eng Perform 26(3):978986. https://doi.org/10.1007/s11665-016-2460-2

Son H-G, Park Y-B, Kweon J-H, Choi J-H (2014) Fatigue behaviour of metal pin-reinforced composite single-lap joints in a hygrothermal environment. Compos Struct 108(1):151-160. https://doi.org/10. 1016/j.compstruct.2013.09.012

Sutherland LS, Guedes Soares C (2011) Impact on marine composite laminated materials. In: Guedes Soares C, Garbatov Y, Fonseca N, Teixeira AP (eds) Marine technology and engineering. Taylor \& Francis Group, London, pp 979-991. https://doi.org/10.13140/RG. 2.1.3592.5201

Sutherland LS, Amado C, Guedes Soares C (2017) Statistical experimental design techniques to investigate the strength of adhesively bonded T-joints. Compos Struct 159:445-454

Sutherland LS, Amado C, Guedes Soares C (2019) Statistical analyses of the effects of bonding parameters and fabrication robustness on the strength of adhesive T-joints. Compos B 175:107063

Tomaso E, Risso G, Gaiotti M, Rizzo CM (2014) Numerical simulation strategies of single lap joints. International Offshore and Polar Engineering Conference, Busan, Korea, 179-186. ISBN 978-1 880653 91-3

Tsai SW, Hahn HT (1980) Introduction to composite materials. CRC Press

Vargas MA, Vázquez H, Guthausen G (2015) Non-isothermal curing kinetics and physical properties of MMT-reinforced unsaturated polyester (UP) resins. Thermochim Acta 611:10-19. https://doi. org/10.1016/j.tca.2014.12.024

Woo K, Nelson JW, Cairns DS, Riddle TW (2013) Effects of defects: part Bprogressive damage modeling of fiberglass/epoxy composite structures with manufacturing induced flaws utilizing cohesive zone elements. Collection of Technical Papers - AIAA/ASME/ASCE/AHS/ASC Structures, Structural Dynamics and Materials Conference, art. no. AIAA 2013-1628. https://doi.org/10.2514/6.2013-1628

Yaacob A, Mokri KN, Puteri Zarina MK, Mun'aim MA, Idrus M, Zakaria ZA, Koto J (2017) Comparative mechanical properties study of resin infusion versus hand laminating for the construction of 12-ft fishing boat. ARPN J Eng Appl Sci 12(6):1954-1960

Yetman JE, Sobey AJ, Blake JIR, Shenoi RA (2017) Mechanical and fracture properties of glass vinylester interfaces. Compos Part B 130:38-45. https://doi.org/10.1016/j.compositesb.2017.07.011

Yetman JE, Sobey AJ, Blake JIR, Shenoi RA (2019) Modelling the variability of skin stiffener debonding in post-cured top-hat stiffened panels. Compos Struct 211:187-195. https://doi.org/10.1016/j. compstruct.2018.11.078

Zimmermann K, Zenkert D, Siemetzki M (2010) Testing and analysis of ultra thick composites. Compos Part B 41(4):326-336. https://doi. org/10.1016/j.compositesb.2009.12.004 